\title{
Relaciones entre espacio ritual y doméstico en sitios Moche del valle Jequetepeque, Perú
}

Relations entre les espaces rituel et domestique dans les sites Moche de la vall

e de Jequetepeque, Pérou

The relationship of ritual and domestic space in the Moche settlements of Jequetepeque valley, Peru

\section{Edward Swenson y Jorge Chiguala}

\section{(2) OpenEdition}

\section{Journals}

Edición electrónica

URL: http://journals.openedition.org/bifea/9866

DOI: 10.4000/bifea.9866

ISSN: 2076-5827

\section{Editor}

Institut Français d'Études Andines

\section{Edición impresa}

Fecha de publicación: 1 agosto 2018

Paginación: 195-216

ISSN: 0303-7495

\section{Referencia electrónica}

Edward Swenson y Jorge Chiguala, «Relaciones entre espacio ritual y doméstico en sitios Moche del valle Jequetepeque, Perú », Bulletin de l'Institut français d'études andines [En línea], 47 (2) | 2018,

Publicado el 08 agosto 2018, consultado el 04 noviembre 2020. URL : http://journals.openedition.org/ bifea/9866 ; DOI : https://doi.org/10.4000/bifea.9866

Les contenus du Bulletin de l'Institut français d'études andines sont mis à disposition selon les termes de la licence Creative Commons Attribution - Pas d'Utilisation Commerciale - Pas de Modification 4.0 International. 


\title{
Relaciones entre espacio ritual y doméstico en sitios Moche del valle Jequetepeque, Perú
}

\author{
Edward Swenson* \\ Jorge Chiguala**
}

\begin{abstract}
Resumen
La construcción de las diferentes variedades de viviendas en estrecha asociación con espacios ceremoniales especializados, tanto en grandes centros con huacas como en asentamientos ubicados en laderas del valle Jequetepeque, señalan concepciones alternativas y diversas del espacio sagrado y cotidiano en el mundo moche. Es el caso en particular de las construcciones domésticas que varían según el grado de permanencia y la temporalidad de su ocupación. Los datos obtenidos en el valle Jequetepeque demuestran que los arqueólogos deben considerar el caracter cultural de las prácticas residenciales así como las concepciones indígenas del espacio doméstico. Al final, el reino doméstico exhibe una formidable diversidad entre los moche (y en la prehistoria andina en general), en cuanto a su construcción cultural y en relación con el estatus social y religioso de sus habitantes.
\end{abstract}

Palabras clave: ritual, viviendas, trashumancia, pasaje, arquitectura

\section{Relations entre les espaces rituel et domestique dans les sites Moche de la vallée de Jequetepeque, Pérou}

\section{Résumé}

La construction de divers types de logements en étroite association avec des espaces cérémoniels spécialisés, aussi bien dans des grands centres comme les huacas que dans les sites situés à flanc de colline dans la vallée de Jequetepeque, indiquent l'existence de conceptions alternatives et diverses de l'espace sacré et quotidien dans le monde moche. C'est en particulier le cas des constructions d'habitat

* University of Toronto, Department of Anthropology, 19 Russell Street, Toronto, ON M5S 2S2, Canada. E-mail: edward.swenson@utoronto.ca

** Ministerio de Cultura - Dirección Desconcentrada de Cultura de Amazonas, Jr. Ayacucho n. ${ }^{\circ}$ 908, Chachapoyas, Amazonas, Perú. E-mail: jchiguala@hotmail.com 
domestique qui diffèrent selon le degré de permanence et les temporalités de leur occupation. Les données de la vallée de Jequetepeque démontrent que les archéologues doivent tenir compte de l'enracinement culturel des pratiques résidentielles ainsi que des conceptions autochtones de l'espace domestique. En fin de compte, il existe une diversité considérable dans la sphère domestique parmi les Moche (et dans la préhistoire andine en général) à la fois en ce qui concerne sa construction culturelle et en relation avec le rang social et religieux de ses habitants.

Mots-clés : rituel, logement, transhumance, paysage, architecture

\title{
The relationship of ritual and domestic space in the Moche settlements of Jequetepeque valley, Peru
}

\begin{abstract}
The construction of dwellings of varied quality and permanence in close association with specialized ceremonial spaces at both large huaca centers and expansive hillside settlements in the Jequetepeque Valley points to alternate and diverse conceptions of sacred and everyday space in the Moche world. In particular, residential constructions varied according to their degree of permanence and the temporality of domestic occupation. The Jequetepeque data demonstrate that archaeologists must consider the cultural embeddedness of residential practices as well as indigenous conceptions of domestic space. In the end, the domestic realm exhibited formidable diversity among the Moche (and in Andean prehistory in general), both in regards to its cultural construction and in relationship to the social and religious status of its inhabitants.
\end{abstract}

Key words: ritual, dwellings, transhumance, landscape, architecture

\section{INTRODUCCIÓN Y PROBLEMA TEÓRICO}

En los últimos veinte años, la arquitectura doméstica ha captado la atención de los arqueólogos que han reconocido de manera creciente que la configuración del espacio residencial es fundamental para la comprensión de los determinados valores culturales y la organización de las prácticas que definen una sociedad particular. El conocido estudio etnográfico de Bourdieu (1973) sobre la vivienda kabyle demostró que el marco espacio-temporal de las actividades diarias tuvo un rol crítico en la socialización y la reproducción de las relaciones de poder naturalizadas. Por otra parte, el espectáculo ritual público y sus correspondientes espacios ceremoniales frecuentemente se han diferenciado del escenario doméstico analizado por los antropólogos que exhiben puntos de vista estructuralistas o materialistas. Las celebraciones rituales juegan un papel importante en la producción ideológica, o en la «conciencia discursiva», según Giddens, mientras que la vivienda común naturaliza las actividades cotidianas o la «conciencia práctica» (habitus) (Bourdieu, 1993; Giddens, 1984; Bradley, 2005; Swenson et al., 2010).

Sin embargo, nuestras recientes investigaciones sobre la intersección del espacio residencial con el espacio ritual en diferentes asentamientos del periodo Moche Tardío en el valle Jequetepeque complican esta dicotomía y se han transformado en un reto para la noción de «vivienda» como un fenómeno espacial y social 
intercultural. Por supuesto, los antropólogos también han reconocido que la vivienda frecuentemente constituye un signo material de órdenes sociales ideales e incluso un símbolo microcósmico de la topografía celestial (Nash, 2009: 206; Rapoport, 1969). Aunque haya un punto de vista que reconozca la construcción cultural y la representación ideológica de la organización de la vivienda, las correspondencias homólogas de este tipo no aparentan haber caracterizado las prácticas espaciales moche. La comprensión de las diversas viviendas en estrecha asociación con espacios ceremoniales especializados tanto en grandes centros con huacas como en asentamientos en laderas en el valle Jequetepeque hacen pensar en concepciones alternativas y diversas del espacio sagrado y cotidiano en el Perú prehispánico.

A la luz del argumento anterior, los antropólogos han considerado con frecuencia la vivienda como una entidad con poco significado consciente («hiposignificante») o como habiendo servido al contrario como un principio simbólico totalizador, como «hipersignificante» (ver Choay, 1986). En la primera afirmación, la vivienda es interpretada primero y antes que nada como el elemento que permite cubrir la subsistencia básica y las necesidades sociales. Epitomiza rutinas diarias al punto que raramente constituye un tema de exegesis religiosas y filosóficas. La vivienda entendida como hipersignificada enfatiza la vivienda física y sus constituyentes como cruciales para la reproducción social y económica, pero subraya al mismo tiempo el simbolismo y significado cosmológicos del espacio residencial — por ejemplo, como un microcosmo en pequeño (Blier, 1987; Nash, 2009: 206)—. Obviamente, las dos interpretaciones polarizadas son simplistas, y el contraste algo artificial exhibido aquí sirve para recordar a los arqueólogos que el significado específico del escenario doméstico debe ser comprendido en el interior de marcos culturales particulares de práctica y no de acuerdo con criterios materialistas o simbólico/estructuralistas universalistas.

Es interesante notar que los materialistas todavía tienden a desestimar la vivienda como crítico para las relaciones micro o macroeconómicas; la producción e intercambio que definen ciertas formaciones sociales son investigadas con más frecuencia en el contexto del mercado, de talleres especializados, o de foros públicos relacionados —el lugar de la «economía política» en oposición a la «economía doméstica» (que es comúnmente percibida como principalmente determinada por la primera) (Blanton, 1994) —. De forma similar, los estructuralistas también relegan el escenario doméstico al reino conceptual de lo privado, femenino, y de lo diario (ver Carsten \& Hugh-Jones, 1995; Guengerich, 2014; Nash, 2009). Ciertamente es importante para los arqueólogos darse cuenta que una correspondencia uno a uno no siempre se mantiene entre la forma física de la vivienda y las relaciones sociales, las que mediaban y representaban materialmente. Las afiliaciones sociales básicas no siempre están confinadas al espacio de la vivienda y pueden incluso haber sido tergiversadas deliberadamente por la configuración y el symbolismo de las moradas. Tampoco la estética de las construcciones residenciales refleja sin ambigüedad el simbolismo y los significados político-religiosos para la que posiblemente fue diseñada. Por ejemplo, Sillar (1996) ha argumentado que una asociación íntima vinculaba la forma y el uso de las chullpas y de las qollcas 
incaicas, definidas por los principios cosmológicos de la muerte, de la fertilidad y de la regeneración. Las primeras sirvieron como repositorios y como casas para deshidratar a los ancestros momificados, y las segundas como depósitos para deshidratar papas, maíz y otros materiales. Obviamente, en este caso, una analogía entre «la vivienda de los vivos» y «la casa de los muertos» (ya sea como homología o inversión) no es pertinente y los significados específicos de las chullpas se perderían si se les comparara exclusivamente con las formas clásicas de viviendas (donde la vivienda es aceptada sin crítica como un principio simbólico y estructural totalizante).

\section{DIVERSIDAD EN LAS CONSTRUCCIONES DOMÉSTICAS Y RITUALES MOCHE}

La extraordinaria diversidad en la construcción, forma y configuración interna de la arquitectura residencial moche constituye uno de los aspectos más sorprendentes de la arqueología de la vivienda moche. Incluso, estudios recientes han demostrado la contemporaneidad de grandes centros moche con sistemas de asentamiento marcadamente diferentes, incluyendo las huacas del Sol y de la Luna y Galindo, que alguna vez se pensó que habían sido ocupadas en periodos distintos (Lockard, 2009). Por ejemplo, el vasto centro urbano de las huacas del Sol y de la Luna alcanzó su auge durante el periodo Moche Tardío (después del 600 d. C.) coincidiendo así temporalmente con la fundación de Galindo en la parte estrecha del valle de Moche (Lockard, 2009; Uceda, 2010).

En este, el mayor de los asentamientos moche, extensas áreas residenciales han sido excavadas. Consisten en una serie de considerables conjuntos de adobe que incluyen patios, corredores, áreas de habitación, talleres, banquetas e instalaciones de almacenamiento (Chapdelaine, 2001: 75; 2009). Una intrincada red de calles, plazas más pequeñas y canales para el abastecimiento de agua interconectaban estos conjuntos residenciales, además de talleres artesanales. Los grandes conjuntos multifuncionales y el sistema de caminos laberínticos indican un alto nivel de planificación urbana (Chapdelaine, 2001; 2002). Chapdelaine argumenta que los conjuntos albergaban grupos corporativos trascendiendo a la familia básica o unidades de parentesco organizadas de acuerdo a la especialización ocupacional. Conjuntos asociados con la producción de cerámica (Uceda \& Armas, 1997; 1998; Chiguala et al., 2007) y abalorios de piedra (Chiguala et al., 2016) han sido analizados, y Chapdelaine (2001: 70-71; 2009) identificó recintos comparables dedicados a la manufactura textil, a la metalurgia, a la producción de chicha y a la crianza de camélidos. Áreas restringidas al interior de los recintos, como accesos sellados, podrían ser el indicio de la presencia de grupos semiindependientes estrechamente integrados que guardaban cuidadosamente la riqueza almacenada así como identidades y actividades específicas del grupo.

Es notorio que las herramientas agrícolas en sitios más pequeños de los valles Moche y Chicama están visiblemente ausentes de las huacas del Sol y de la Luna, indicando que la numerosa población urbana no estuvo en su mayoría dedicada 
a la producción primaria de alimentos (Chapdelaine, 2001). En efecto, los restos arquitectónicos y funerarios al interior de los conjuntos sugieren que ceramistas, metalurgos y otros artesanos que residían en el sector urbano constituían una comunidad privilegiada, tratada con condescendencia por el Estado (Chapdelaine, 2001: 73; Uceda \& Armas, 1998: 108). Con base en restos arquitectónicos excavados, Chapdelaine incluso argumenta que las clases bajas residían fuera de la ciudad, aunque participaban en los rituales públicos y en las tareas laborales, incluyendo la manufactura de adobes y el mantenimiento de canales en Cerro Blanco (ver Topic, 1982).

En marcado contraste, la forma más común de arquitectura residencial en la llanura de Galindo (Llanura A2), al sur de los conjuntos políticos y religiosos de elite de las así llamadas Cercaduras, consiste en estructuras rectilíneas más pequeñas hechas de piedra que servían de base a muros de caña (Bawden, 1982: 310314; Lockhard, 2009: 281-282). Estas construcciones comprenden generalmente cuatro cámaras dedicadas a cocinar, almacenar y vivir/dormir. Una clara red de calles, canales y plazas definían el paisaje urbano de las huacas del Sol y de la Luna; representaban grandes áreas residenciales y conjuntos artesanales que están claramente ausentes en Galindo. Adicionalmente, una comunidad urbana socialmente más heterogénea estaba presente y caracterizaba al sitio de Galindo (incluyendo agricultores de clase baja, aparentemente ausentes en el sitio huacas del Sol y de la Luna); residía en las laderas alrededor del núcleo del sitio. Bawden interpreta los cambios dramáticos en la planificación urbana de Galindo como significando «profundos cambios en la estrategia de poder y su base ideológica» (Bawden, 1996: 288). Mucha de su investigación se ha enfocado en el marcado abismo entre las cercaduras horizontales y las icónicas y verticalmente orientadas pirámides en las huacas del Sol y de la Luna. Estas diferencias en la base de datos arqueológica han sido tradicionalmente explicadas como reflejando ya sea divisiones étnico-temporales ya sea la variabilidad en la economía política y las estrategias de la elite para el control social e ideológico. Sin embargo, lo que no ha sido considerado en profundidad es la interrelación espacial, contextual y posiblemente simbólica de distintas construcciones de viviendas con el espacio ceremonial público y entre estos dos importantes asentamientos (no se sabe si han sido contemporáneos en el periodo tardío - AD 600-800-). Galindo y las huacas del Sol y de la Luna son fácilmente diferenciados por su arquitectura religiosa monumental pero también en cuanto a sus unidades básicas de socialidad y corresidencialidad, como se puede deducir del tamaño y configuración de sus muy diferentes construcciones domésticas. Grandes grupos corporativos definidos por la especialización ocupacional y extensos pero delimitados conjuntos arquitectónicos como los que existen en las huacas del Sol y de la Luna contrastan con las estructuras menores que anclaban las unidades familiares nucleares o pequeñas familias extendidas del asentamiento contemporáneo de Galindo. Sin embargo, esto no quiere decir que la organización social cooperativa estaba ausente en Galindo; simplemente pudo haber trascendido la vivienda física individual que puede haber estado investida de poco significado social o poder representativo (nuevamente, una correspondencia entre la vivienda física y las unidades básicas de sociabilidad no puede ser aceptada). 
Es interesante observar que los entierros fueron sepultados en banquetas al interior de ambos tipos de estructuras en los dos sitios mencionados (Bawden, 2001; Uceda, 2010), y las prácticas rituales sin duda formaron una importante dimensión de la vida diaria en las residencias moche. Sin embargo, vale considerar que los ritos conducidos al interior de distintas viviendas pudieran haber diferido de manera significativa, del mismo modo que ha variado la forma de las estructuras mismas de las viviendas. En otras palabras, no debe suponerse que una forma específica de «ritual doméstico» existía en las comunidades moche (o que el ritual fuera siquiera concebido como específico a la vivienda misma). Por ejemplo, las celebraciones ceremoniales y el consumo de chicha constituían una de las principales actividades asociadas con los múltiples conjuntos cercados en las huacas del Sol y de la Luna (Uceda, 2010). Estas celebraciones, que se sustentaban en la preparación de alimentos en grandes cocinas comunales, fueron escenificadas en plazas. No puede descartarse que estas fiestas involucraran a representantes del Estado moche o cabezas de linajes residiendo en conjuntos vecinos. Aunque tales rituales de banquetes puedan haber funcionado en parte para fomentar la solidaridad entre corresidentes y transmitir la generosidad y prestigio de la «sociedad de la casa» en cuestión, pudieron también haber fomentado la disolución o reconfiguración de los límites entre grupos corresidenciales. En otras palabras, los principales eventos rituales estuvieron posiblemente divorciados de las preocupaciones cotidianas inmediatas y de la economía doméstica de sus habitantes. Estos torneos de consumo de alimentos sin duda vinculaban el intercambio supravivienda y la competencia que reverberaba a más de un nivel las relaciones sociopolíticas urbanas al interior de los exclusivos confines de un conjunto particular. Ciertamente, los eruditos andinos han señalado por mucho tiempo que la producción y consumo fueron realizados más allá del marco conceptual o espacial de la vivienda (Nash, 2009: 230). En realidad, lo mismo puede decirse de las prácticas rituales, ya sea de naturaleza cotidiana o excepcional.

La extraordinaria diversidad de la arquitectura ceremonial y de viviendas en la región de Moche está reflejada en la notable heterogeneidad de los asentamientos del valle Jequetepeque, donde hemos realizado investigaciones desde el año 2001 (fig. 1). El valle Jequetepeque estuvo caracterizado por una de las mayores concentraciones de centros urbanos y ceremoniales durante el periodo Moche Tardío (600-900 d. C.), incluyendo los sitios de San José de Moro, Cerro Chepén, Talambo, Pacatnamu, huaca Estacas y huaca Colorada (Castillo, 2010; Castillo \& Donnan, 1994; Rosas, 2007; Dillehay et al., 2009; Swenson, 2004; Swenson et al., 2010; 2011). Aunque San José de Moro estuvo definido por funciones funerarias especializadas, es evidente que las personas viajaron al importante asentamiento por periodos definidos de tiempo. Sin embargo, nunca ha sido un centro residencial importante con viviendas permanentes (Castillo, 2010). De hecho, las estructuras efímeras de viviendas (temporales) constituyen el tipo residencial más habitual en el valle y están comúnmente identificadas por una densa dispersión de cerámica superficial que carece de contextos arquitectónicos definidos. Estaban principalmente construidas con estructuras de quincha asentadas en muros de piedra (fig. 2). Los muros encierran pisos enlucidos o superficies de uso más 


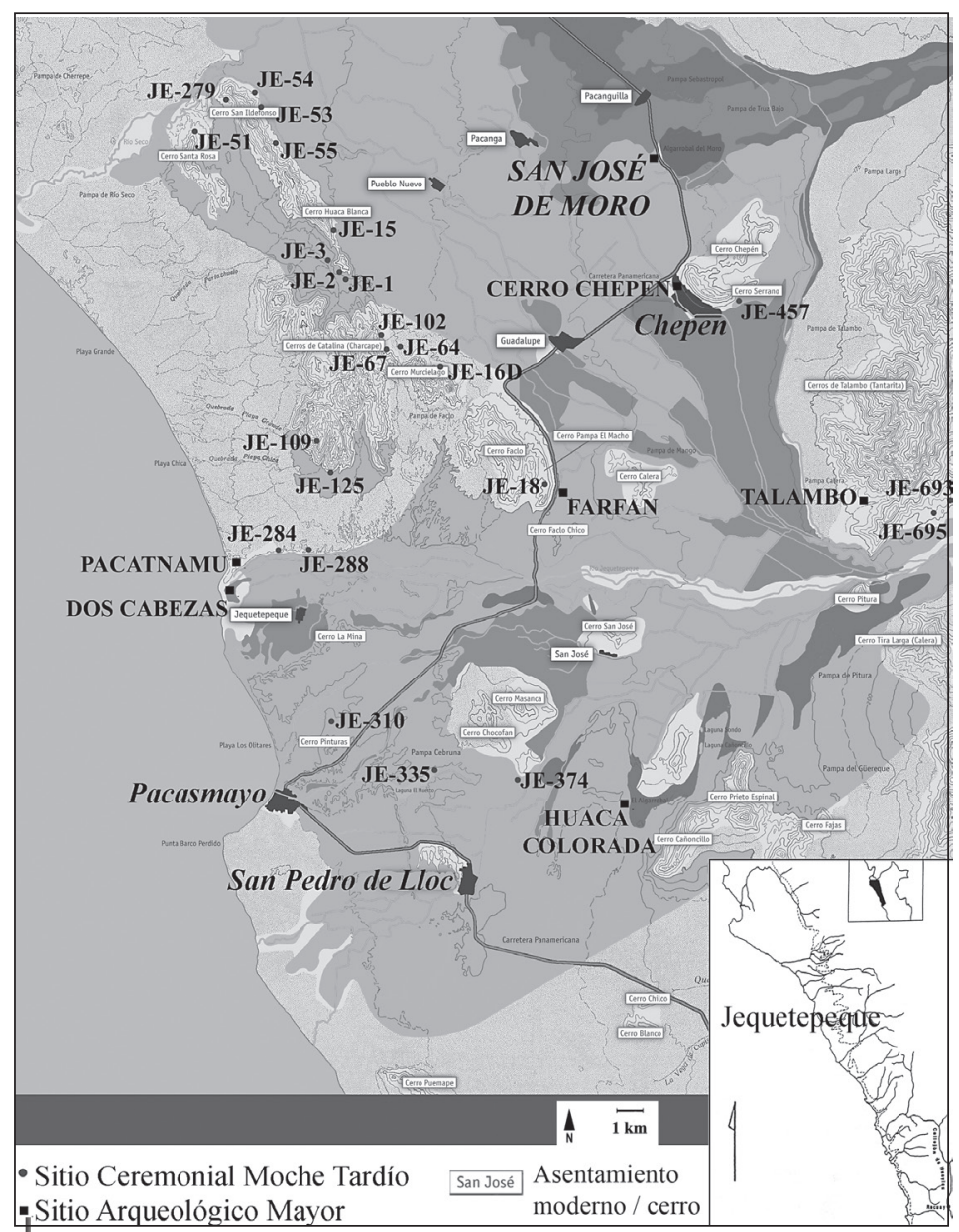

Figura 1- Mapa del valle Jequetepeque ilustrando la ubicación de huaca Colorada y los asentamientos rurales con arquitectura ceremonial

(c) Proyecto Jatanca-Huaca Colorada

informales de arena. Pequeñas aldeas agrícolas localizadas en las pampas desérticas y las quebradas del lado norte del valle estaban determinadas frecuentemente por toscos paravientos semicirculares construidos de piedras o cantos rodados (fig. 2). Evidentemente, poco trabajo u ornamentación estética fueron invertidos en la construcción de estas residencias, tanto al interior de los grandes centros como de los asentamientos rurales dispersos.

\section{VALLE JEQUETEPEQUE}

El descubrimiento de numerosos sitios arqueológicos distinguidos por una yuxtaposición de arquitectura doméstica y ceremonial en las zonas marginales 


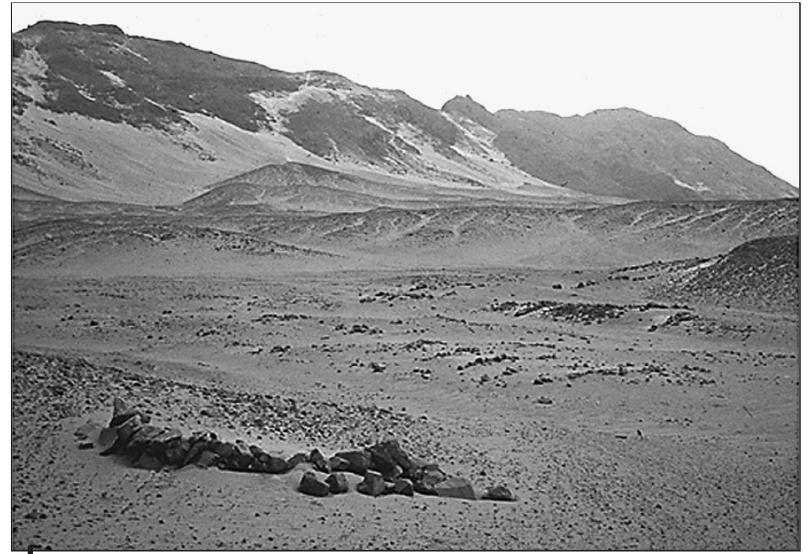

Figura 2 - Paravientos semicirculares construidos de piedras pequeñas localizadas en la pampa desértica del valle Jequetepeque

(c) Proyecto Jatanca-Huaca Colorada del valle —principalmente colinas costeras y campamentos en el desierto- acredita adicionalmente las variadas tradiciones del espacio ocupado en la región de Jequetepeque (fig. 1). Once de estos sitios fueron investigados por los autores en los años 2001 y 2002 (Swenson, 2004) y consisten en terrazas residenciales densamente compactadas, pequeñas estructuras y prominentes plataformas con rampa, todas construidas con piedra y grava local. Las terrazas aparentan haber sido usadas como espacios para viviendas, áreas de producción, y para deshidratar y almacenar alimentos como lo indica

la prospección, la recolección estratificada de cerámica y las excavaciones a pequeña escala (fig. 3) (Swenson, 2004). La forma más común de arquitectura ceremonial identificada en los asentamientos al interior del territorio moche son montículos aterrazados de múltiples escalones con rampas y patios conspicuamente ubicados (fig. 4). La escala de los edificios varía considerablemente, desde rectángulos de 25 hasta $65 \mathrm{~m}$, por 1 hasta $12 \mathrm{~m}$ de altura (Swenson, 2004). Al respecto, Bawden (1982) menciona que las contrapartes construidas de adobe de tales estructuras (comparables en escala y configuración) en el centro contemporáneo de Galindo son denominadas «tablados» (ver también, Shimada, 1994). En una primera inspección, las plataformas coronadas por estrados en Jequetepeque aparentan ser versiones miniaturizadas de las masivas pirámides que formaban el corazón de las ciudades tradicionales y contemporáneas moche. Las estructuras de este tipo están comúnmente representadas en la cerámica moche como escenarios importantes de representación ritual e intercambio social (Bawden, 1982; ver Swenson, 2006).

Como lo corrobora la iconografía, concentraciones estadísticamente altas de
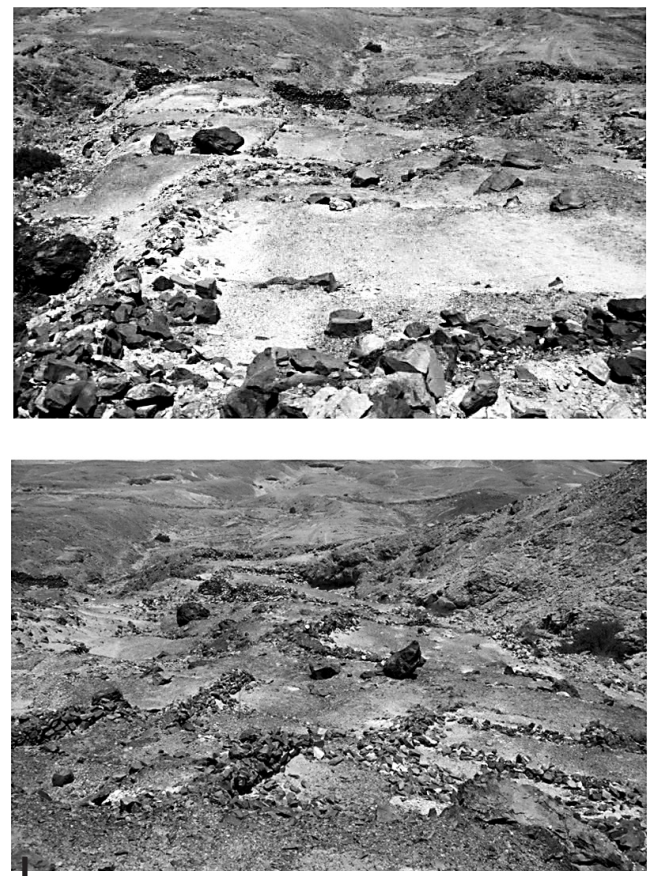

Figura 3 - Terrazas residenciales densamente compactadas del sitio de San Ildefonso, valle Jequetepeque

cántaros para festines, cerámica decorada (c) Proyecto Jatanca-Huaca Colorada 
e instrumentos musicales (fig. 5) recogidos de la superficie de las plataformas ceremoniales en Jequetepeque indican que estas construcciones fueron teatros de eventos rituales cuidadosamente orquestados. La representación indudablemente comprendía danzas, cantos y elaborados torneos de hospitalidad y consumo festivo

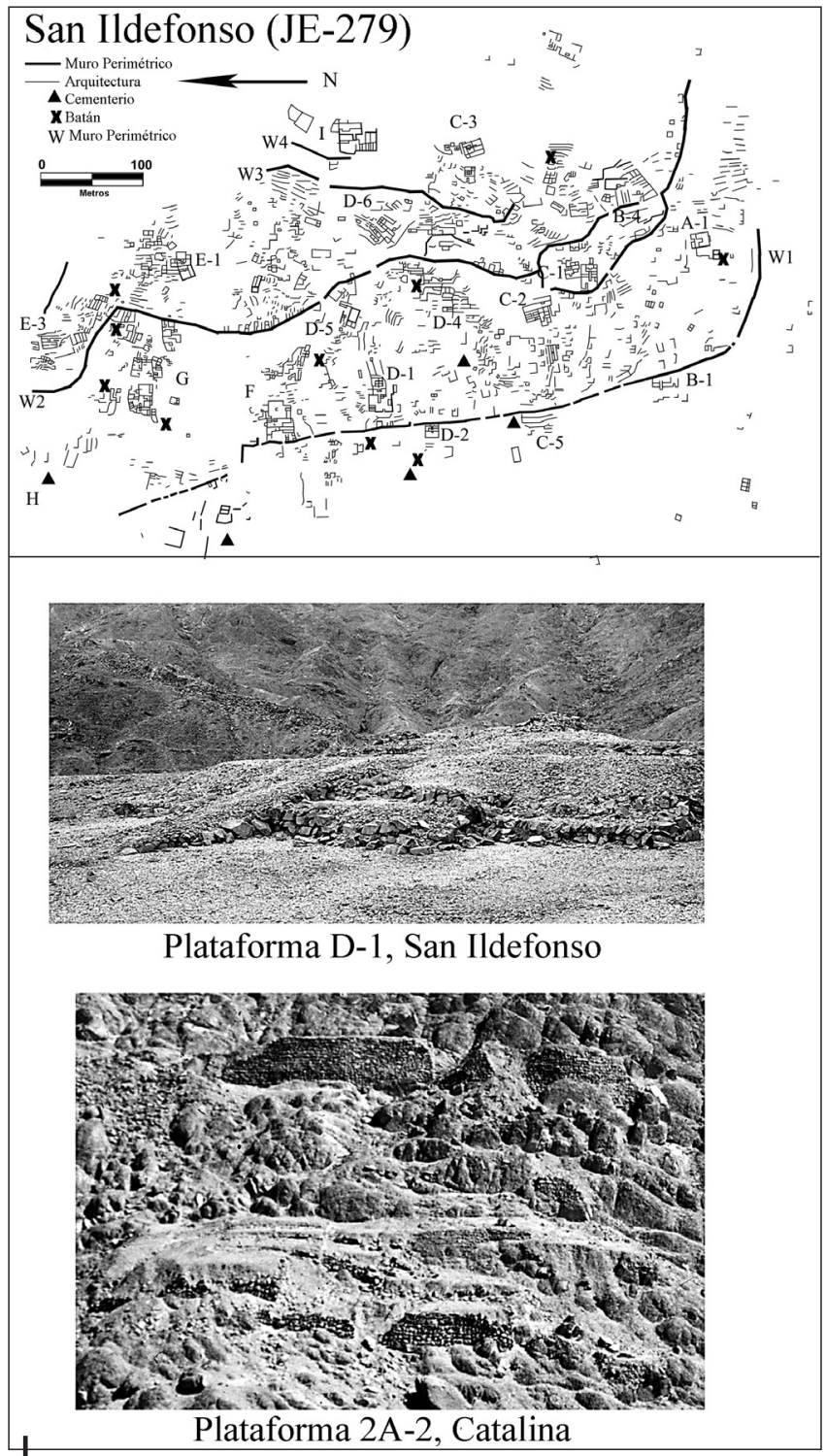

Figura 4 - Plano del asentamiento de San Ildefonso, ilustrando la ubicación de cuatro masivos muros perimétricos y múltiples estructuras aterrazadas con rampa (registro superior) y fotografías de plataformas para festines del Jequetepeque rural (registro inferior)

(C) Proyecto Jatanca-Huaca Colorada 
(Swenson, 2006). Los múltiples lugares ceremoniales en la parte rural del valle Jequetepeque exhibían una variedad arquitectónica específica al sitio, lo que sugiere que la producción ritual era prerrogativa de las comunidades rurales locales (Swenson, 2004; 2006; 2007; 2008). De hecho, las diferentes tradiciones arquitectónicas que habrían prescrito ceremonias coreografiadas de manera distintiva caracterizaron estos asentamientos dispersos en el valle Jequetepeque. Sin embargo, este tipo de sitios está definido por la pluralidad de construcciones religiosas; ningún monumento único domina asentamientos específicos como el foco de la autoridad política y religiosa. Esta configuración de estructuras religiosas replicadas en sitios como San Ildefonso en la parte norte del valle (Fig. 4) difiere notablemente de Pampa Grande y de los sitios moche anteriores distinguidos por una clara jerarquía interna a nivel de las formas arquitectónicas. En San Ildefonso, diecisiete plataformas con rampa se distribuyen de

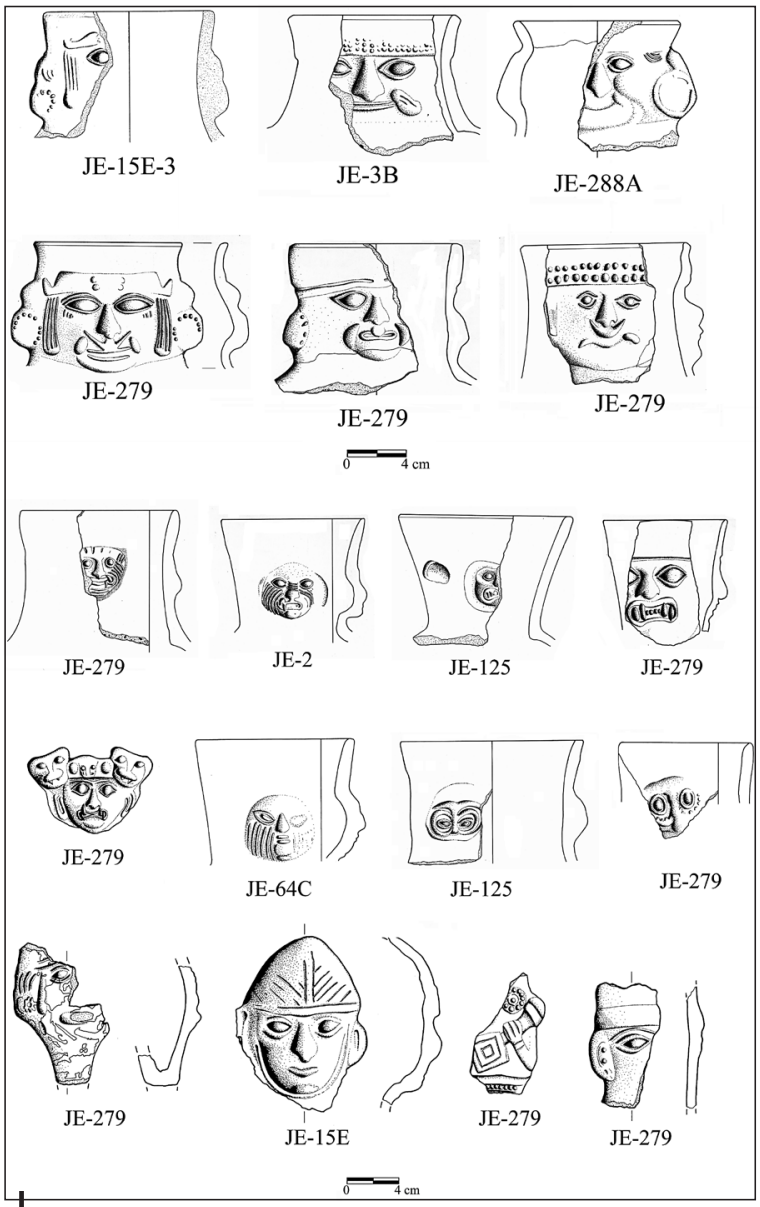

Figura 5 - Vasijas de chicha de elites masculinas, figurillas y instrumentos musicales (fila inferior) recogidos en los sitios ceremoniales del territorio de Jequetepeque

(c) Proyecto Jatanca-Huaca Colorada manera homogénea entre las terrazas domésticas y los conjuntos rectilíneos de almacenamiento de varias elevaciones ubicadas detrás de los grandes muros de la fortificación. Festines y celebraciones de la religión moche se hicieron frecuentes, incluso «derregulados», en la región de Jequetepeque (Swenson, 2006; 2012a; 2012c). Por lo tanto el contenido de las ceremonias escenificadas aparenta haber sido similar entre asentamientos ceremoniales a pesar de los diferentes marcos experimentales estructurando la representación ritual. Esta evidencia sugiere que los ritos de celebración mediaban relaciones políticas competitivas y jerárquicas en el valle bajo del Jequetepeque durante el periodo Moche Tardío (Dillehay, 2001; Swenson, 2004).

Es importante notar que muchos de estos sitios con múltiples estructuras con rampa estuvieron fortificados como lo estuvieron la mayoría de los asentamientos 
grandes a intermedios en el valle Jequetepeque durante el periodo Moche Tardío (Castillo, 2010; Dillehay, 2001; Swenson, 2004, 2012a). Parecen haber estado designados como refugios y centros de intensa celebración política y ritual, incluyendo posiblemente la representación de guerra ritual (Swenson, 2008). Las unidades residenciales son difíciles de definir en estos asentamientos, más allá de posibles agrupaciones de terrazas domésticas con relación a una plataforma con rampa. Es evidente que las construcciones de viviendas carecieron de permanencia y ocupación a largo plazo (como en San José de Moro). De hecho, la excavación sugiere que estos sitios estuvieron habitados episódicamente, posiblemente siguiendo un calendario ceremonial particular, ciclo de festividades, o periodos de guerra e inseguridad generalizada.

La variedad elevada de tipos de asentamientos en Jequetepeque sugiere con gran probabilidad que el desplazamiento y los espacios de ocupación dispersos estaban altamente valorados, y que las construcciones domésticas al interior de estos diferentes asentamientos estaban consecuentemente inculcadas con significados distintivos. Sin embargo, las viviendas informales deben haber albergado prácticas cotidianas comparables, esenciales para el mantenimiento y la reproducción de asociaciones corresidenciales probablemente fluidas. Al parecer, en los sistemas interconectados de múltiples y «transitorias» construcciones residenciales, las familias o las comunidades que regresaban, no necesariamente reocupaban las mismas viviendas «temporales». Esto contrasta marcadamente con los modelos de asentamiento con horizontalidad económica (asociados con los climas diversos de los diferentes pisos de la sierra). En los Andes Centrales meridionales, Gose (1991) describe la práctica de la residencia dual y la disolución estacional así como la reconstitución de grupos domésticos —una analogía que podría tener relevancia para la comprensión de las particularidades de los datos de los asentamientos en Jequetepeque-.

Ciertamente, el valle Jequetepeque aparenta haber estado caracterizado por el movimiento interno regular de personas, una tradición de asentamientos fluida y dinámica que desafía las comprensiones antropológicas de la permanencia espacial de la vivienda física. Un cierto valor fue puesto en la circulación y domesticidad, por lo menos temporal entre un gran segmento de la población de Jequetepeque durante el periodo Moche Tardío. Sin embargo, esta trashumancia estuvo obviamente mediada por circunstancias económicas e ideológico religiosas muy alejadas de las prácticas migratorias de las sociedades recolectoras y de sus campamentos asociados.

La diversidad de la organización espacial y de las temporalidades variables de ocupación doméstica en Jequetepeque se refleja también en el sitio grande de Cerro Chepén en el lado norte del valle. Castillo y su equipo sostienen que este centro estuvo ligado al culto de la sacerdotisa en San José de Moro. En el sector monumental del sitio, los conjuntos rectangulares construidos de piedra (a menudo con dos o tres plantas) se parecen a los estilos arquitectónicos de la sierra; Rosas $(2003 ;$ 2010) sostiene que este asentamiento, ubicado en una posición alta y dominante en el valle, representa un asentamiento intrusivo de 
cajamarquinos. Las estructuras en la Zona Monumental son mucho más grandes y permanentes que la mayoría de las estructuras domésticas en el valle, y parecían servir de residencias y espacios para las elites y para actividades diversas como los rituales. Al interior de los ambientes, Rosas (2010: 547, 590) identificó diferentes espacios como dormitorios, depósitos y zonas de producción de alimentos. Espacios ceremoniales especializados existen en Cerro Chepén (Plataformas I, II, y III en la Zona Monumental y plataformas con rampas en el Sector Bajo no-elite), y parece que los «colonos» han ocupado el sitio de una manera más permanente, lo que constituye un escenario bien diferente al de San José de Moro, de Huaca Colorada, o de las aldeas dispersas en la región (Cusicanqui, 2010). Sin embargo, la extensa zona de Cerro Chepén Bajo consistía en más de 700 terrazas y plataformas construidas sobre las laderas del cerro, bajo la muralla perimétrica de la Zona Monumental. Estas construcciones son más modestas que los grupos-patio «Huari» de la zona monumental pero parecen que fueron organizadas en sectores habitacionales separados por senderos, escaleras, y corredores (Cusicanqui, 2010: 48). El Sector Habitacional de Cerro Chepén Bajo se caracterizó también por espacios públicos y ceremoniales asociados con evidencia de festines; es posible que peregrinos y pobladores migratorios ocuparan las numerosas terrazas durante estaciones específicas como en San Ildefonso. La estratigrafía superficial encontrada en esta zona podría apoyar esta conclusión (Cusicanqui, 2010: 54; Johnson, 2013: 57).

Nuestras recientes investigaciones arqueológicas en el sitio de Huaca Colorada indican adicionalmente una considerable diversidad en la construcción y uso del espacio residencial en el valle Jequetepeque. La alargada construcción piramidal de Huaca Colorada, construida sobre una duna modificada, constituye el mayor asentamiento moche en la margen sur del río Jequetepeque (figs. 1 y 6). Investigaciones indican que este sitio sirvió como sede de una comunidad poderosa y probablemente políticamente independiente, encabezada por una elite religiosa y económica especializada. La excavación de la cima de la huaca principal permitió poner al descubierto una red de muros superpuestos delineando cámaras, corredores y localidades de producción que formaron parte de una residencia de alto estatus así como recintos rituales privados y por lo menos semipúblicos. Los sacrificios hallados en asociaciones con plataformas, una cocina centralizada, y amplias cámaras ceremoniales conteniendo ofrendas de sacrificios humanos fueron todos descubiertos muy cerca de la cima de la huaca (fig. 7) (Swenson, 2012b; 2014). Las excavaciones revelaron que el terraplén superior del monumento estuvo asociado con figuras de estatus elevado que abrazaban los principios religiosos y políticos moche, como ejemplifican los grabados de los muros, un mural de una serpiente, la construcción de altares y la iconografía religiosa, incluyendo el descubrimiento de cerámica de línea fina Moche $\mathrm{V}$ y Cajamarca (fig. 8).

La configuración espacial única y las características distintivas del monumento resaltan la extraordinaria diversidad en la estructura de asentamientos y la organización política del Horizonte Medio en Jequetepeque. La huaca es inusual en su combinación de estructuras domésticas y religiosas, demostrando la ausencia de 

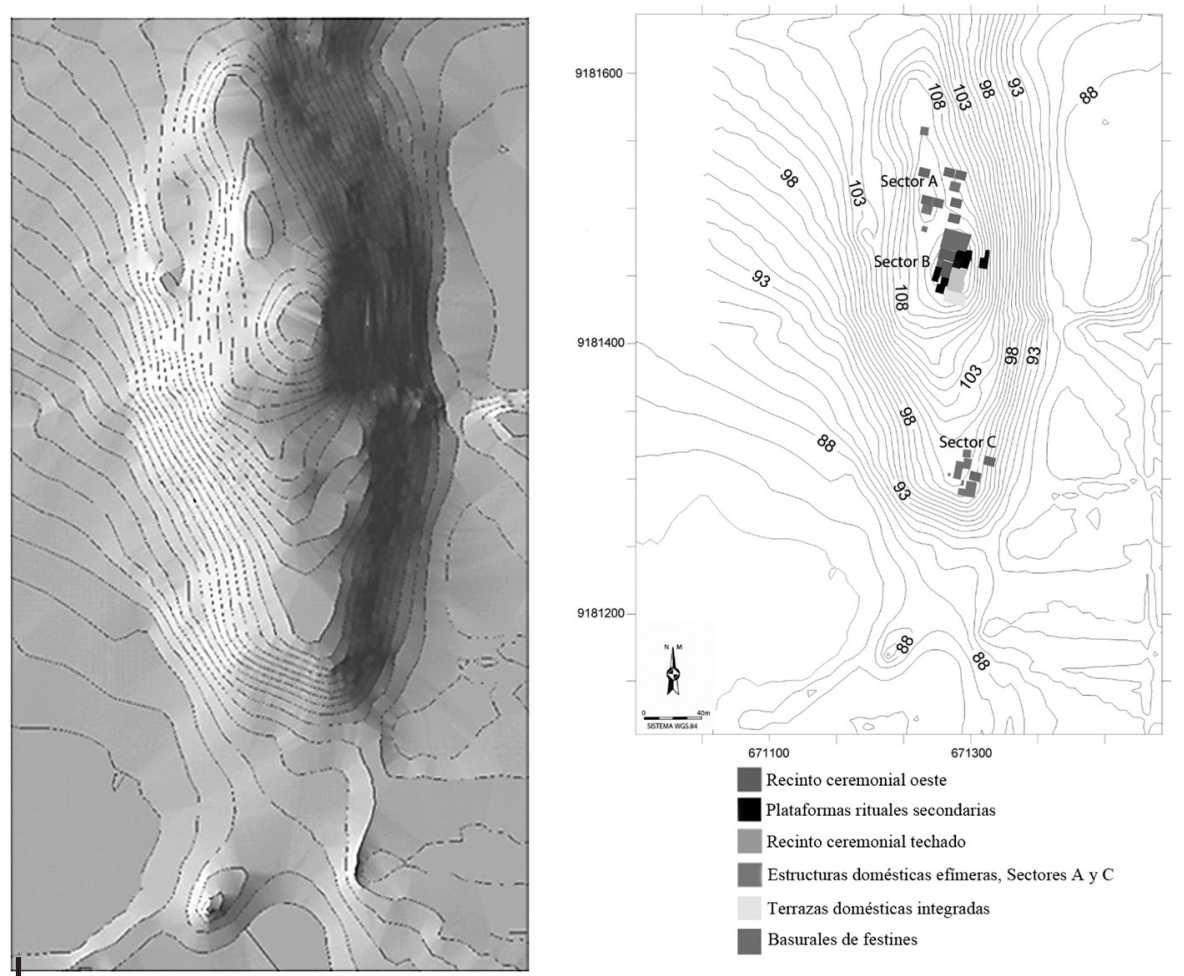

Figura 6 - Plano tridimensional de Huaca Colorada y mapa ilustrando la ubicación de las unidades de excavación abiertas durante la temporada 2010

(c) Proyecto Jatanca-Huaca Colorada

una separación uniforme de lo sagrado y lo profano en la ideología espacial moche. La asociación de construcciones residenciales multifuncionales con las de alto estatus parece indiscutible. Una gran cantidad de cerámica de línea fina, cántaros para festines, ornamentos de cobre, conchas de Spondylus y diversos y variados restos alimenticios nutritivos (incluyendo coca, ají, huesos de camélidos, maní, frutas andinas, etc.) fueron registrados en las unidades abiertas durante nuestras primeras seis temporadas de excavaciones. De hecho, se recuperaron más cerámica de línea fina y objetos de cobre en Huaca Colorada que en todas las excavaciones de sitios Moche Tardío con arquitectura ceremonial del territorio urbano y rural del valle Jequetepeque (Swenson, 2004; 2012a; Swenson et al., 2011).

Es lógico preguntarse si alguna de las diferencias notorias en estructuras residenciales en el valle Jequetepeque y al interior del sitio de Huaca Colorada es simplemente producto de divisiones socioeconómicas. Es cierto que las construcciones más elaboradas en la cima de la huaca fueron testigos de una intensa ocupación y de, por lo menos, diez fases de renovación, algunas de las cuales permitieron completar la reconfiguración de cuartos habitacionales y espacios ceremoniales semipúblicos (Swenson, 2012b). La notable permanencia y elaboración de las residencias de la huaca contrastan con las de caracter temporal que se hallan 

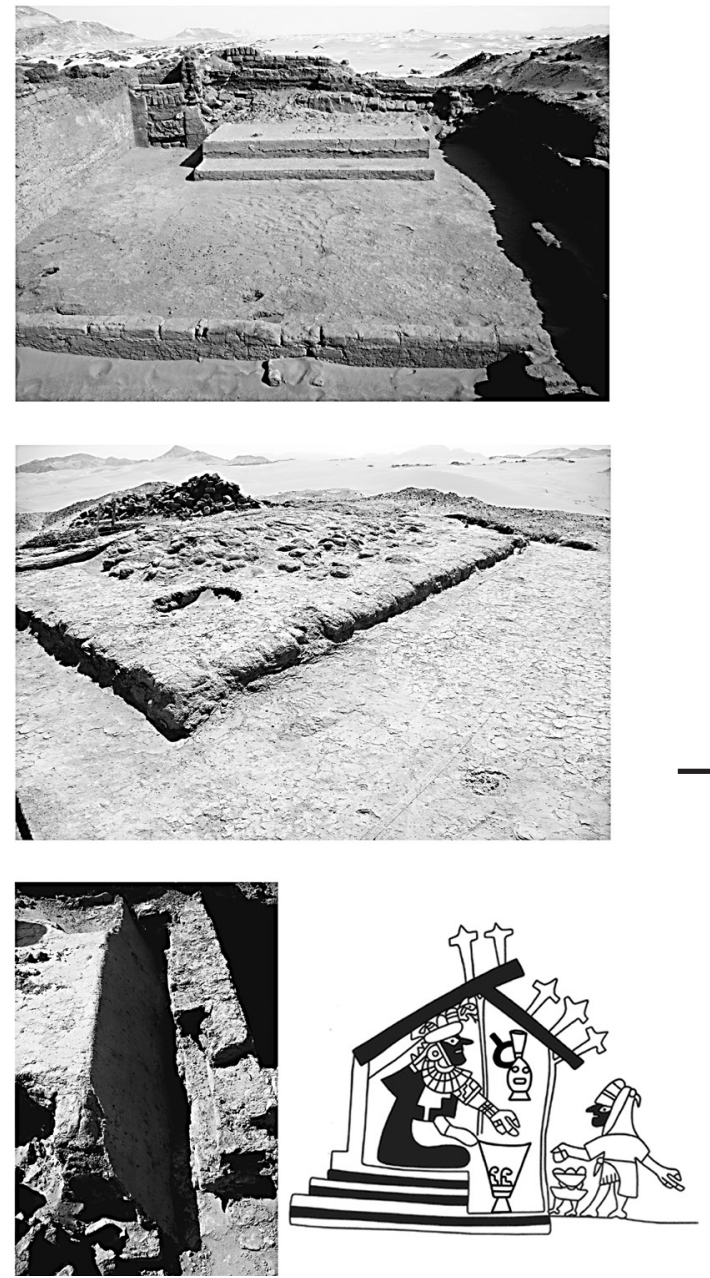

Figura 7 - Plataformas de adobe datando de diferentes fases de ocupación excavadas en Huaca Colorada

La representación moche de línea fina de un estrado techado se parece a las plataformas de Huaca Colorada en términos de forma, escala y emplazamiento de los postes (redibujado de Donnan, 1978: página 66, Fig. 104)

(C) Proyecto Jatanca-Huaca Colorada

dispersas en todo el valle. En cambio, se encontró correspondencia directa al interior de las estructuras de los conjuntos del sitio huacas del Sol y de la Luna que fueron objeto de ocupación a largo plazo y de renovación sistemática (Van Gijseghem, 2001). Van Gijseghem nota que los elaborados conjuntos en el sitio huacas del Sol y de la Luna divergen notablemente de las viviendas más pequeñas y modestas que fueron abandonadas después de uno o dos pisos de ocupación. Interpreta los datos en términos de alto estatus y poder de asociaciones de linajes individuales que habitaron los conjuntos urbanos.

Huaca Colorada es caracterizada también por extensas zonas domésticas localizadas en las proyecciones a manera de «espolones» situadas al norte y sur del complejo ceremonial y residencial de elite (fig. 6) (Swenson, 2012b; Swenson \& Warner, 2012). Nuestras excavaciones preliminares en los sectores A y $\mathrm{C}$ hacia el sur han mostrado que la ocupación fue de duración relativamente 


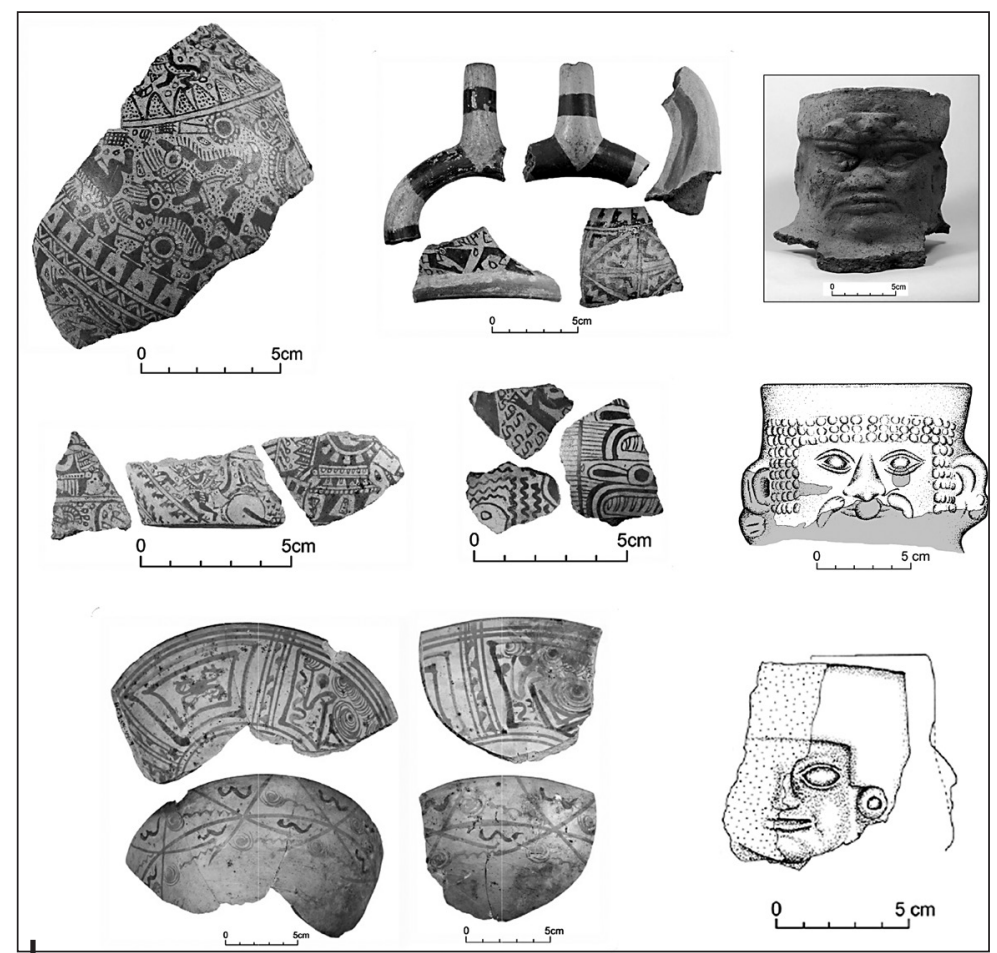

Figura 8 - Cerámica de línea fina de Cajamarca y vasijas para chicha recuperadas en el sector monumental de Huaca Colorada

(C) Proyecto Jatanca-Huaca Colorada

corta y asociada con poblaciones no elitistas; en muchas instancias, no más de tres o cuatro pisos fueron hallados en esta área (una profundidad estratigráfica no mayor a $60-70 \mathrm{~cm}$ ). Estas superficies de uso estuvieron asociadas con muros bajos de adobe que sostenían estructuras de caña (fig. 9). Hoyos de poste, fogones, broches de cobre, piruros y figurinas fueron hallados con frecuencia al interior de este espacio residencial (fig. 10). Incluso, es interesante que se hayan descubierto en esta extensa zona construcciones más informales, completamente desasociadas de los pisos enlucidos. Estos espacios residenciales y productivos consistían simplemente en cortas alineaciones de adobes que fueron colocados directamente sobre arena suelta (figs. 9 y 11). Construcciones provisionales de este tipo aún se construyen en partes del valle Jequetepeque, y varios ejemplos como este, documentados en Huaca Colorada, fueron asociados con gruesos depósitos de arena con huellas de combustión y restos orgánicos (hallados usualmente al costado de los alineamientos de adobes — como se caracterizan las alineaciones modernas-; Gálvez Mora, comunicación personal). De hecho, la producción de cobre y de cerámica fue realizada en el Sector $\mathrm{C}$ y posiblemente en otras zonas del sitio, como es evidente por el descubrimiento de escoria de cobre, ornamentos de cobre, pequeños crisoles y moldes de cerámica (Swenson 2012b; Swenson \& Warner, 2012) (fig. 12). Aún no está claro si la producción metalúrgica 
estuvo centralizada y bajo la supervisión de la elite de Huaca Colorada. Nuestra evidencia principal sugiere que pudo haber estado parcialmente incluida al interior de contextos domésticos, donde unidades familiares ejercían un control parcial sobre los medios de producción. Posiblemente ofrecían tributo en productos terminados de cobre al cacique que los dirigía o a los oficiales religiosos del sitio. Quizá este intercambio se hacía a través de ceremonias festivas y otros rituales — Como también lo indican los datos arqueológicos (Swenson et al., 2010)_. De hecho, es posible que las comunidades se congregaran en la huaca durante ciertos periodos del año para cumplir con las obligaciones tributarias y festivales religiosos. Es significativo que un número relativamente alto de cerámica de línea fina moche fuera recuperada en el Sector $\mathrm{C}$ junto con figurinas decoradas con simbolismo religioso moche (fig. 10). Sin embargo, una concentración mucho más

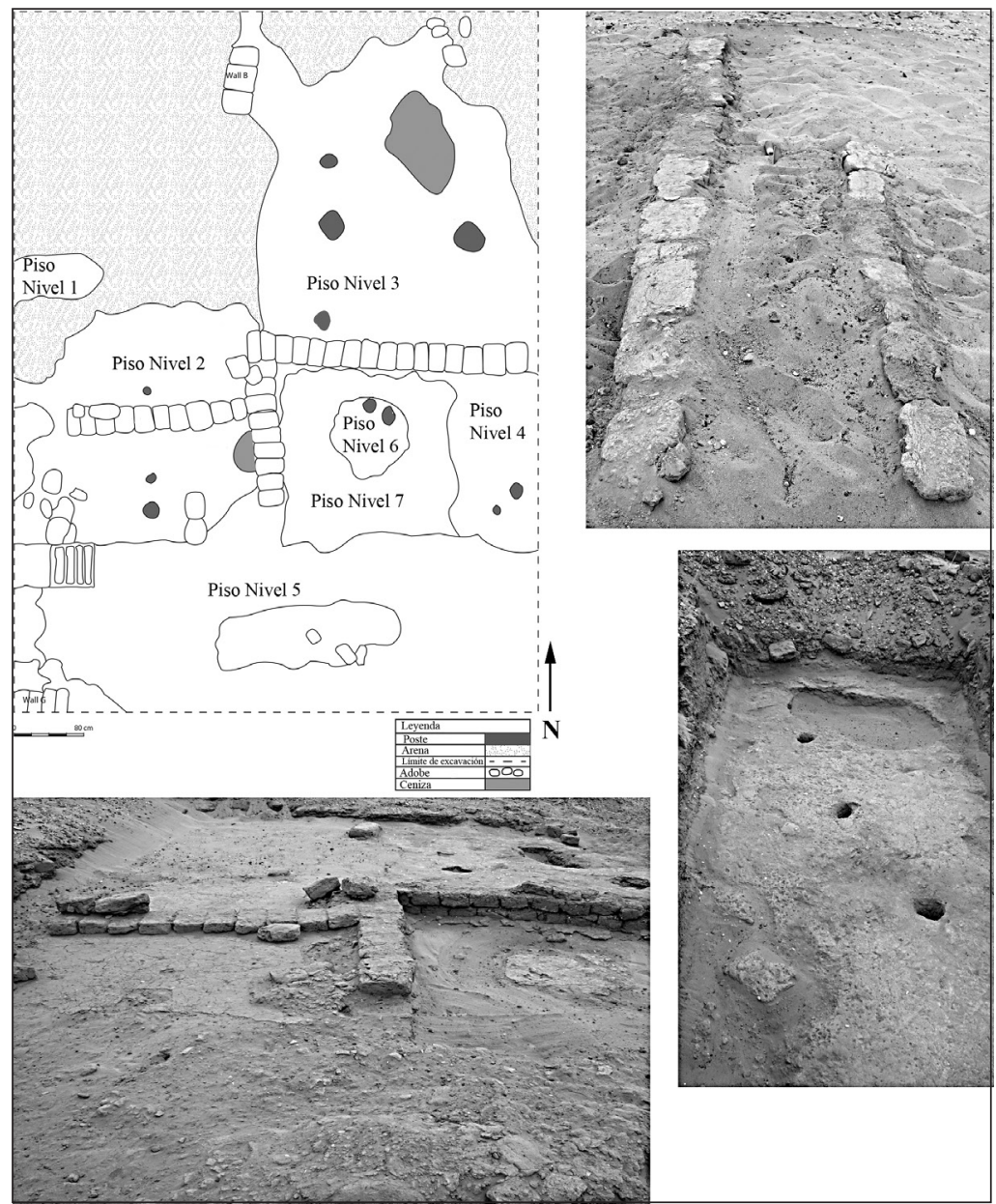

Figura 9 - Estructuras domésticas variadas en el Sector C de Huaca Colorada (C) Proyecto Jatanca-Huaca Colorada 


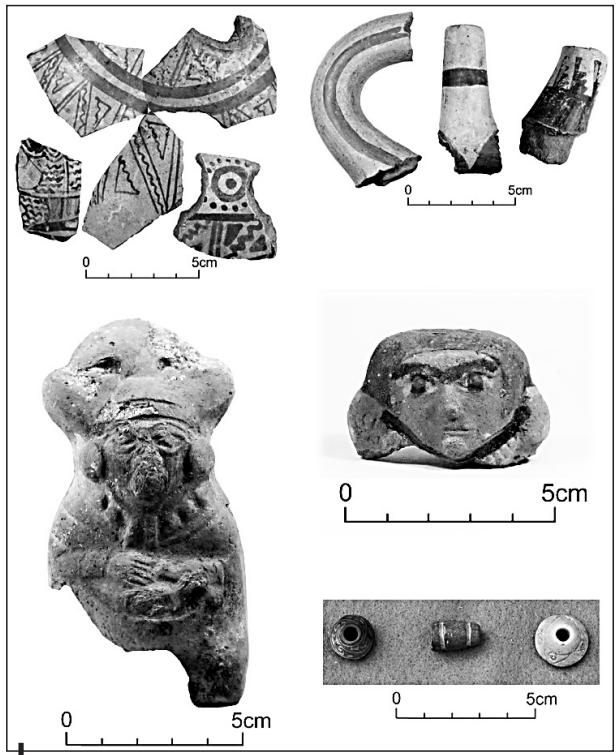

Figura 10 - Cerámica de línea fina, piruros y figurinas recuperados en el Sector C residencial de Huaca Colorada

(C) Proyecto Jatanca-Huaca Colorada

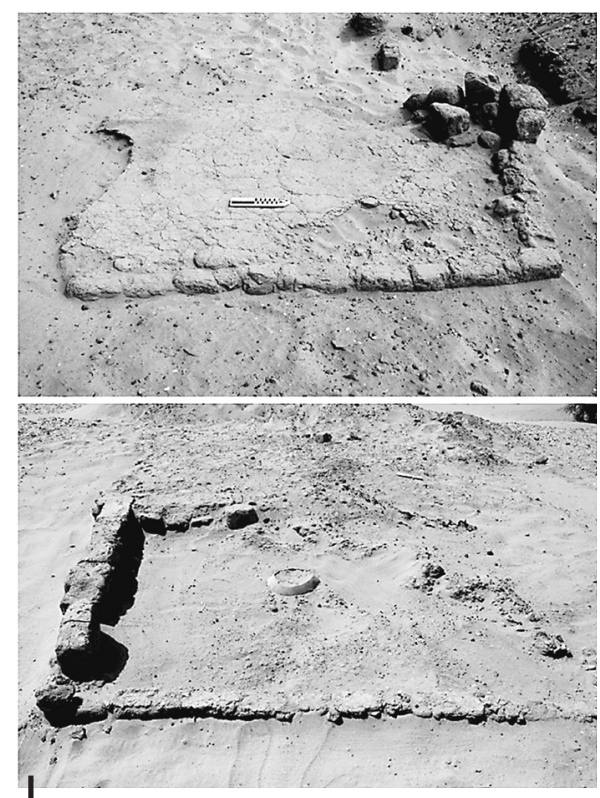

Figura 11 - Pisos formales enlucidos asociados con pisos de arena informal en el Sector C de Huaca Colorada

(C) Proyecto Jatanca-Huaca Colorada alta de platos Cajamarca Medio fue recuperada en los basurales asociados a la cima del recinto ceremonial en Huaca Colorada; las diferencias de estatus, reflejadas en los materiales tanto arquitectónicos como artefactuales son fácilmente aparentes en el asentamiento. Empero, vale la pena considerar el contexto distintivo y sagrado de la producción artesanal y de ciertas actividades residenciales, como se refleja en la elevada cantidad de finos artefactos moche recuperados en el área doméstica. Dos figurinas femeninas en el Sector $C$ sugieren que «el ritual doméstico» como está definido genéricamente por los antropólogos constituía probablemente una práctica importante de los residentes de bajo estatus que vivían y trabajaban allí. No obstante, vale la pena considerar que estos mismos individuos pueden haber residido en caseríos más pequeños alrededor de Huaca Colorada durante otras temporadas o incluso en los asentamientos de laderas con arquitectura ceremonial de piedra

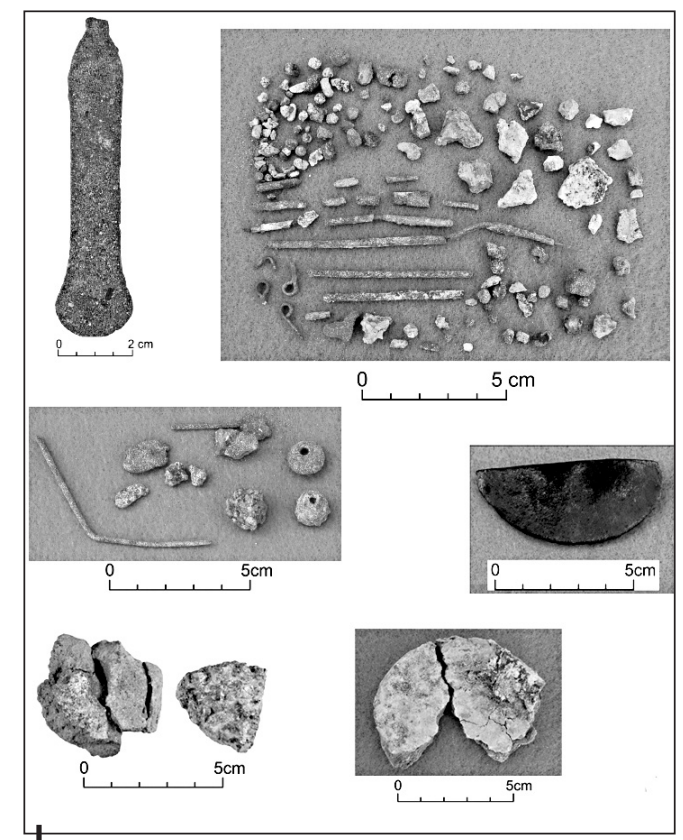

Figura 12 - Restos de cobre en varios estados de producción y herramientas de producción

(c) Proyecto Jatanca-Huaca Colorada 
mencionados anteriormente. Dado el movimiento cíclico entre construcciones informales, es probable que la vida residencial en Huaca Colorada fuera concebida y experimentada de forma diferente al interior del marco de específicas representaciones religiosas escenificadas en el monumento. La asociación intercultural de producción metalúrgica con la eficacia ritual podría ser relevante para comprender el contexto político y ceremonial de la producción de cobre y las residencias provisionales en Huaca Colorada (Blakely, 2006; Trevelyan, 2004; Swenson \& Warner, 2012).

\section{CONCLUSIÓN}

Para concluir, el patrón de variación en la forma, calidad y configuración de la arquitectura doméstica no se correlaciona necesariamente con las diferencias en el estatus social, pero sí con construcciones culturales particulares del espacio y del paisaje. Al tomar en consideración la considerable variabilidad de construcciones residenciales en el valle Jequetepeque, ya sea las aldeas temporales construidas en la vecindad de los campos agrícolas, las estructuras aterrazadas en sitios ceremoniales fortificados en la campiña, ya sea los abrigos de quincha en la zona doméstica no elitista de Huaca Colorada, se hace evidente que estas construcciones residenciales separadas no corresponden a distintos grupos étnicos o clases socioeconómicas. En cambio, aparenta haber una expectativa para las comunidades de cambiar posiblemente de constitución y tamaño para mantener múltiples residencias de acuerdo con los ritmos de los ciclos económicos, religiosos y posiblemente militares. Un tema importante que merece atención y que será tema de otro artículo es la explicación detallada de la variabilidad de las configuraciones domésticas y de la temporalidad de ocupación en el valle. Proponemos que esta diversidad haya sido el resultado de la organización religiosa y social específica del valle Jequetepeque. En particular, parece que un calendario litúrgico o días de fiesta han parcialmente determinado el movimiento recurrente de comunidades en el valle y las construcciones efímeras en asentamientos distintos. En periodos específicos, grupos sociales han ocupado un sitio como San Ildefonso para venerar una huaca asociada con quizás un «macro ayllu» compuesto por linajes más pequeños que han mantenido las construcciones temporales dispersas en el valle durante las estaciones de la siembra y de la cosecha. Durante varias semanas o meses la comunidad confederada participaba en festines para honorar a la huaca o huacas de este nivel de cooperación y para satisfacer las necesidades económicas y rituales de kurakas menores. Parece que la guerra ritual y la competencia entre grupos menores jugaron un papel importante en esta categoría de sitio (ver Swenson, 2012a). Durante otros meses del año, y a una escala más amplia que un macro ayllu, linajes u otros grupos sociales en el sur del valle eran obligados a participar en la producción artesanal y en observancias religiosas relacionadas en Huaca Colorada que, claramente, sirvió como la sede de un respetado cacique moche o huaca. Por lo tanto, es posible que grupos de todo el valle pasaran un periodo determinado en sitios como San José de Moro, Cerro Chepén y Huaca 
Colorada (siguiendo un cargo o rotación) para cumplir con las obligaciones de tributo y ritual del culto de la sacerdotisa y del dios u oráculo asociados con Huaca Colorada (Castillo, 2001; Johnson, 2013: 55). La participación en festines y obras económicas del culto podría haber intensificado un sentimiento de comunidad (imaginativa) entre una numerosa pero diversa población.

Actividades como dormir, preparar alimentos, almacenar a corto plazo, desechar basura, criar niños, tejer, hacer ritos de curación, partos, etc, probablemente diferían poco en estos tres tipos de asentamientos/residencias identificados entre las poblaciones plebeyas en Jequetepeque. Sin embargo, los ritmos, resonancia emocional y conceptualización de la «vida doméstica» fueron indudablemente modificados por el escenario mayor en el que estas prácticas cotidianas más invariables fueron conducidas. Ciertamente, es justo asumir que una clara división entre lo puramente doméstico y el ritual público nunca ocurrió en la sociedad moche y que no había una ideología singular de «vivienda» como un constructo general (ver Banning, 2011; Bowser \& Patton, 2004; Guengerich, 2014; Hendon, 1996; Robin, 2002; Robin \& Rothschild, 2002). Los datos de Jequetepeque demuestran que los arqueólogos deben considerar el marco cultural de las prácticas residenciales así como las concepciones indígenas sobre el espacio doméstico. Finalmente, lo doméstico no puede divorciarse de las construcciones culturales y las experiencias de paisajes más amplios de los que formaban parte (Robin \& Rothschild, 2002). De hecho, la noción de domesticidad en el pensamiento moche estaba probablemente muy alejada de las concepciones occidentales de la casa o la vivienda.

\section{Referencias citadas}

BANNING, E. B., 2011 - So Fair a House: Göbekli Tepe and the Identification of Temples in the Pre-Pottery Neolithic of the Near East. Current Anthropology, 52 (5): 619-660.

BAWDEN, G., 1982 - Galindo: A Study in Cultural Transition During the Middle Horizon. In: Chan Chan: Andean Desert City (M. Moseley \& K. Day, eds.): 285-320; Albuquerque: University of New Mexico Press.

BAWDEN, G., 1996 - The Moche, 375 pp.; Cambridge: Blackwell Publishers.

BAWDEN, G., 2001 - The Symbols of Late Moche Social Transformation. In: Moche Art and Archaeology in Ancient Peru (J. Pillsbury, ed.): 285-305; New Haven: Yale University Press.

BLAKELY, S., 2006 - Myth, Ritual, and Metallurgy in Ancient Greece and Recent Africa, 342 pp.; Cambridge: Cambridge University Press.

BLANTON, R., 1994 - Houses and Households: A Comparative Study, 285 pp.; New York: Plenum.

BLIER, S. P., 1987 - The Anatomy of Architecture: Ontology and Metaphor in Batammaliba Architectural Expression, 332 pp.; Chicago: University of Chicago Press.

BOURDIEU, P., 1973 - The Berber House or the world reversed. In: Rules and Meanings (M. Douglas ed.): 98-110; New York: Hammondsworth. 
BOURDIEU, P., 1993 - The Field of Cultural Production: Essays on Art and Literature, 336 pp.; New York: Polity Press.

BOWSER, B. \& PATTON, J., 2004 - Domestic spaces as Public Places: an Ethnoarchaeological Case Study of Houses, Gender, and Politics in the Ecuadorian Amazon. Journal of Archaeological Method and Theory, 11 (2): 157-181.

BRADLEY, R., 2005 - Ritual and Domestic Life in Prehistoric Europe, 234 pp.; London-New York: Routledge.

CARSTEN, J. \& HUGH-JONES, S., 1995 - About the House: Levi-Strauss and Beyond, 300 pp.; New York: Cambridge University Press.

CASTILLO, L. J., 2001 - The Last of the Mochicas: a view from the Jequetepeque valley. In: Moche Art and Archaeology in Ancient Peru (J. Pillsbury, ed.): 307-332; New Haven: Yale University Press.

CASTILLO, L. J., 2010 - Moche Politics in the Jequetepeque Valley: A Case for Political Opportunism. In: New Perspectives in Moche Political Organization (J. Quilter \& L. J. Castillo, eds.): 1-24; Washington D.C.: Dumbarton Oaks.

CASTILLO, L. J. \& DONNAN, C. B., 1994 - Los Mochica del Norte y los Mochica del Sur. In: Vicús (K. Makowski \& C. B. Donnan, eds.): 143-181; Lima: Banco de Crédito del Perú.

CHAPDELAINE, C., 2001 - The Growing Power of a Moche Urban Class. In: Moche Art and Archaeology in Ancient Peru (J. Pillsbury, ed.): 69-87; New Haven: Yale University Press.

CHAPDELAINE, C., 2002 - Out in the Streets of Moche: Urbanism and Sociopolitical Organization at a Moche IV Urban Center. In: Andean Archaeology I: Variations in Sociopolitical Organization (W. H. Isbell \& H. Silverman, eds.): 53-88; New York: Plenum.

CHAPDELAINE, C., 2009 - Domestic Life In and Around the Urban Sector of the Huacas of Moche Site, Northern Peru. In: Domestic Life in Prehispanic Capitals: A Study of Specialization, Hierarchy, and Ethnicity (L. Manzanilla \& C. Chapdelaine, eds.): $181-$ 196; Ann Arbor: University of Michigan Press.

CHIGUALA, J., ALMONACID, C., ORBEGOSO, M., ROJAS, D. \& SANDOVAL, M., 2016 La Integración Funcional de los Conjuntos Arquitectónicos 17 y 35 como parte de un Bloque Arquitectónico en el Núcleo Urbano. In: Investigaciones en la Huaca de La Luna 2005 (S. Uceda, R. Morales \& C. Rengifo, eds.): 141-209; Trujillo: Facultad de Ciencias Sociales de la Universidad Nacional de Trujillo, Patronato Huacas del Valle de Moche.

ChiGualA, J., RODRíGuEZ, F., MORALES, A., SOTO, P., LÓPEZ, M. \& GÓMEZ, J., 2007 - Áreas de actividad del Conjunto Arquitectónico 21 y su integración al Bloque Constructivo № 2. In: Proyecto Arqueológico Huaca de La Luna, Informe Técnico 2006 (S. Uceda \& R. Morales, eds.): 89-155; Trujillo: Facultad de Ciencias Sociales de la Universidad Nacional de Trujillo.

CHOAY, F., 1986 - Urbanism and Semiology. In: The City and the Sign, an Introduction to Urban Semiotics (M. Gottdiener \& A. Lagopoulos eds.): 160-171; New York: Columbia University Press.

CUSICANQUI MARSANO, S., 2010 - Investigaciones en el sitio arqueológico Cerro Chepén: Levantamiento topográfico en la Zona Monumental y excavaciones arqueológicas en el Sector Habitacional de Bajo Rango. In: Programa Arqueológico San José de Moro: Informe de Excavación Temporada 2010 (L. J. Castillo, ed.): 4759; Lima: Pontificia Universidad Católica del Perú. 
Relaciones entre espacio ritual y doméstico en el valle Jequetepeque, Perú

DILLEHAY, T. D., 2001 - Town and Country in Late Moche Times: A View from Two Northern Valleys. In: Moche Art and Archaeology in Ancient Peru (J. Pillsbury, ed.): 259-284; New Haven: Yale University Press.

DILLEHAY, T., D., KOLATA, A. \& SWENSON, E., 2009 - Paisajes Culturales en el Valle del Jequetepeque: Los Yacimientos Arqueológicos, 329 pp.; Trujillo: Ediciones Sian.

DONNAN, C. B., 1978 - Moche Art of Peru. Pre-columbian symbolic communication, xvi + 205 рp.; Los Angeles: Museum of Culture History, University of California.

GIDDENS, A., 1984 - The Constitution of Society: Outline of a Theory of Structuration, xxxvii +402 pp.; Cambridge: Polity Press.

GOSE, P., 1991 - House Rethatching in an Andean Annual Cycle: Practice, Meaning, and Contradiction. American Ethnologist, 18 (1): 39-66.

GUENGERICH, A., 2014 - Monte Viudo: Residential Architecture and the Everyday Production of Space in a Chachapoya Community; Chicago: Universidad de Chicago, Tesis de Doctorado.

HENDON, J., 1996 - Archaeological Approaches to the Organization of Domestic Labor: Household Practice and Domestic Relations. Annual Review of Anthropology, 25: 45-61.

JOHNSON, I., 2013 - Investigaciones Arqueológicas en el Asentamiento Moche Medio, Sector 1 del Sitio Arqueológico Cerro Chepén. In: Programa Arqueológico San José de Moro: Informe de Excavación Temporada 2012 (L. J. Castillo, ed.): 50-81; Lima: Pontificia Universidad Católica del Perú.

LOCKARD, G., 2009 - The Occupational History of Galindo, Moche Valley, Peru. Latin American Antiquity, 20 (2): 279-302.

NASH, D., 2009 - Household Archaeology in the Andes. Journal of Archaeological Research, 17 (3): 205-261.

RAPOPORT, A., 1969 - House Form and Culture, 146 pp.; New Jersey: Prentice Hall, Englewood Cliffs.

ROBIN, C., 2002 - Outside of Houses: The Practices of Everyday life at Chan Nòohol, Belize. Journal of Social Archaeology, 2 (2): 245-268.

ROBIN, C. \& ROTHSCHILD, N. A., 2002 - Archaeological Ethnographies: Social Dynamics of Outdoor Space. Journal of Social Archaeology, 2 (2): 159-172.

ROSAS RINTEL, M., 2007 - Nuevas perspectivos acerca del colapso Moche en el bajo Jequetepeque: Resultados Preliminares de la segunda campaña de investigación del proyecto arqueológico Cerro Chepén. Bulletin de L'Institut Français d'Études Andines, 36 (2): 221-240.

ROSAS RINTEL, M., 2010 -Cerro Chepén and the Late Moche Collapse in the Jequetepeque Valley, North Coast of Perú; Albuquerque: Universidad de Nuevo Mexico, Tesis de Doctorado.

SHIMADA, I., 1994 - Pampa Grande and the Mochica Culture, 323 pp.; Austin: University of Texas Press.

SILLAR, B., 1996 - The Dead and the Drying: Techniques for Transforming Peoples and Things in the Andes. Journal of Material Culture, 1 (3): 259-289.

SWENSON, E., 2004 - Ritual and Power in the Urban Hinterland: Religious Pluralism and Political Decentralization in Late Moche Jequetepeque, Peru; Chicago: Universidad de Chicago. Tesis de Doctorado.

SWENSON, E., 2006 - Competitive Feasting, Religious Pluralism, and Decentralized Power in the Late Moche Period. In: Andean Archaeology III: North and South (W. Isbell \& H. Silverman, eds.): 112-142; New York: Springer. 
SWENSON, E., 2007 - Adaptive Strategies or Ideological Innovations? Interpreting Sociopolitical Developments in the Jequetepeque Valley of Peru during the Late Moche Period. Journal of Anthropological Archaeology, 26 (2): 1-30.

SWENSON, E., 2008 - San Ildefonso and the Popularization of Moche Ideology in the Jequetepeque Valley. In: Arqueología Mochica: Nuevos Enfoques (L. J. Castillo, H. Bernier, G. Lockard \& J. Rucabado, eds.): 411-432; Lima: Fondo Editorial Pontificia Universidad Católica del Perú.

SWENSON, E., 2012a - Warfare, Gender, and Sacrifice in Jequetepeque Peru. Latin American Antiquity, 23 (2): 167-193.

SWENSON, E., 2012b - Moche Ceremonial Architecture as Third Space: The Politics of Place-Making in Ancient Peru. Journal of Social Archaeology, 12 (1): 3-28.

SWENSON, E., 2012C - Los Fundamentos Cosmológicos de las Interacciones Moche Sierra durante el Horizonte Medio en Jequetepque. Boletín de Arqueología PUCP, 16: 79-104. Los Rostros de Wari: Perspectivas Interregionales sobre el Horizonte Medio (L. J. Castillo \& J. Jennings, eds.); Lima: Fondo Editorial Pontificia Universidad Católica del Perú.

SWENSON, E., 2014 - The Materialities of Place-Making in the Ancient Andes: A Critical Appraisal of the Ontological Turn in Archaeological Interpretation. Journal of Archaeological Method and Theory. DOI 10.1007/s10816-014-9202-2.

SWENSON, E., CHIGUALA, J. \& WARNER, J., 2010 - Proyecto de Investigación Arqueológica Jatanca-Huaca Colorada, Valle de Jequetepeque. Informe Final. Temporada 2009, 246 pp.; Lima: Instituto Nacional de Cultura.

SWENSON, E., CHIGUALA, J. \& WARNER, J., 2011 - Proyecto de Investigación Arqueológica Jatanca-Huaca Colorada, Valle de Jequetepeque. Informe Final. Temporada 2010, 387 pp.; Lima: Instituto Nacional de Cultura.

SWENSON, E. \& WARNER, J., 2012 - Crucibles of Power: Forging Copper and Forging Subjects at the Moche Ceremonial Center of Huaca Colorada, Peru. Journal of Anthropological Archaeology, 31 (3): 314-333.

TOPIC, T., 1982 - The Early Intermediate Period and its Legacy. In: Chan Chan: Andean Desert City (M. Moseley \& K. Day, eds.): 255-284; Albuquerque: University of New Mexico Press.

TREVELYAN, A. M., 2004 - Miskwabki, Metal of Ritual: Metallurgy in Precontact Eastern North America, 360 pp.; Lexington: University of Kentucky Press.

UCEDA, S., 2010 - Theocracy and Secularism: Relationships between the Temple and Urban Nucleus and Political Change at the Huacas de Moche. In: New Perspectives on Moche Political Organization (J. Quilter \& L. J. Castillo, eds.): 132-158. Washington, D.C.: Dumbarton Oaks.

UCEDA, S. \& ARMAS, J., 1997 - Los talleres alfareros en el centro urbano Moche. In: Investigaciones en la Huaca de la Luna 1995 (S. Uceda, E. Mujica \& R. Morales eds.): 93-104; Trujillo: Universidad Nacional de Trujillo-Facultad de Ciencias Sociales, Unión de Cervecerías Backus \& Johnston, Municipalidad Provincial de Trujillo.

UCEDA, S. \& ARMAS, J., 1998 - An Urban Pottery Workshop at the Site of Moche, North Coast of Peru. In: Andean Ceramics: Technology, Organization, and Approaches (I. Shimada, ed.): 91-110; Philadelphia: Museum Applied Science Center for Archaeology, University of Pennsylvania Museum of Archaeology and Anthropology. MASCA Research Papers in Science and Technology (15).

VAN GIJSEGHEM, H., 2001 - Household and family at Moche Peru: An analysis of building and residence patterns in a prehispanic urban center. Latin American Antiquity, 12 (3): 257-273. 